\title{
Efficacy of Cytoreductive Surgery with Hyperthermic Intraperitoneal Chemotherapy in the Management of Malignant Ascites
}

\author{
Reese W. Randle, MD ${ }^{1}$, Katrina R. Swett, MS ${ }^{2}$, Douglas S. Swords, BA ${ }^{1}$, Perry Shen, MD, \\ FACS $^{1}$, John H. Stewart, MD, FACS ${ }^{1}$, Edward A. Levine, MD, FACS ${ }^{1}$, and Konstantinos I. \\ Votanopoulos, MD, PhD, FACS ${ }^{1}$ \\ ${ }^{1}$ Surgical Oncology Service in the Department of General Surgery, Wake Forest University, \\ Winston-Salem, NC \\ ${ }^{2}$ Department of Biostatistics, Wake Forest University, Winston-Salem, NC
}

\begin{abstract}
Background-In peritoneal surface disease, accumulation of malignant ascites represents a difficult problem to treat, with adverse impact on quality of life. The role of cytoreductive surgery (CRS) with hyperthermic intraperitoneal chemotherapy (HIPEC) in controlling malignant ascites is not well defined.
\end{abstract}

Methods-A retrospective analysis of a prospectively maintained database of 1,000 procedures was performed. Type of malignancy, resolution of ascites, duration and agent of chemoperfusion, performance status, resection status, morbidity, mortality, and survival were reviewed.

Results-Ascites was found in 299 patients (310 procedures) either before or during exploration. A total of $142(46 \%)$ procedures were performed for appendiceal primary disease, $53(17 \%)$ colorectal, 20 (6\%) gastric, $45(15 \%)$ mesothelioma, and 26 (8\%) ovarian. A total of $288(93 \%)$ patients had resolution of ascites by 3 months' follow-up. In patients with ascites, complete cytoreduction was obtained in 15 versus $59 \%$ when ascites was not present $(p<0.001)$. In the group of patients who had their ascites controlled, 243 of 288 (84\%) had resection with residual macroscopic disease (R2 status). Twenty-two patients ( $7 \%$ ) had persistent ascites at 3 months' follow-up, 19 (86 \%) of whom had an R2 resection. Univariate analysis revealed that type of primary disease, resection status, duration or agent of chemoperfusion, and performance status did not predict failure.

Conclusions-CRS-HIPEC is effective in controlling ascites in $93 \%$ of patients with malignant ascites, even when a complete cytoreduction is not feasible. Ascites is predictive of incomplete cytoreduction and worse overall survival. Although complete cytoreduction remains the goal of this procedure, HIPEC can provide palliative value in selected patients with malignant ascites.

(C) Society of Surgical Oncology 2013

kvotanop@wakehealth.edu.

Presented at the Eighth International Symposium on Regional Cancer Therapies, Indian Wells, CA, February 2013.

CONFLICT OF INTEREST The authors declare no conflict of interest.

DISCLOSURE None. 
In patients with peritoneal surface disease (PSD), malignant ascites is associated with a short life expectancy, ranging from weeks to a few months. ${ }^{1,2}$ A modest increase in life expectancy of up to 4-5 months has been observed with modern chemotherapy, depending on the primary disease. ${ }^{3,4}$ Symptomatic treatment with paracentesis improves distension and dyspnea, but effects are short-lived as the ascites quickly reaccumulates, and cognitive and emotional quality of life continue to decline. ${ }^{5}$

Overall, current therapeutic options for patients with malignant ascites are limited to palliation. ${ }^{6-8}$ Laparoscopic hyperthermic intraperitoneal chemotherapy (HIPEC) without cytoreductive surgery (CRS) can offer a palliative improvement by decreasing ascites, but it leaves the tumor burden unaddressed. ${ }^{7,9-15}$ CRS-HIPEC addresses tumor burden, but recovery takes up to 3-6 months, and all data regarding its ability to control ascites come from small series. ${ }^{16-21}$

Our primary objective was to examine the efficacy of CRS-HIPEC in controlling malignant ascites in patients in whom a complete cytoreduction was attempted but not accomplished as a result of the volume or distribution of disease. The secondary aim was to create a preoperative scoring system that correlates the presence of malignant ascites with the ability to achieve complete cytoreduction.

\section{METHODS}

A prospective database containing 1,000 CRS-HIPEC procedures from 1992 to 2012 was retrospectively reviewed. Initial selection included all cases where malignant ascites was documented on preoperative computed tomography (CT) or during surgical exploration. Patients were analyzed on the basis of demographics, primary tumors, extent of resection, perfusion time, and perfusion agent. Morbidity, mortality, and survival were also reviewed. IRB approval was obtained.

An ascites scoring system was created on the basis of the distribution of ascites in the peritoneal cavity on preoperative $\mathrm{CT}$ of the abdomen and pelvis with the patient in supine position. The purpose of the ascites score was to measure and compare patients with variable abdominal cavity size, primary malignancy, and disease extension. The ascites score was retrospectively graded in each case where the preoperative CT scan was available as follows: The abdominal cavity was divided into nine regions similar to those used in calculating the peritoneal carcinomatosis index except that the small bowel did not comprise an additional four regions (Fig. 1). ${ }^{22}$ When ascites was present within a particular region, 1 point was assigned, without ascites a score of 0 was assigned. Thus, preoperative ascites was graded on a scale from 0-9 using this point system. For those cases where a preoperative CT was not available but the operative note indicated volume $>3.51$ of ascites, a score of 9 was applied.

All selected patients, underwent CRS-HIPEC as described in our previously published protocol. ${ }^{23}$ The aim of the cytoreductive surgery was to remove all gross disease before HIPEC. Upon opening (via midline incision in all cases), all ascites was drained. The chemotherapeutic agent was selected on the basis of the primary tumor, added to the 
perfusate, and the heat was titrated to maintain an outflow temperature of $40{ }^{\circ} \mathrm{C}$. The perfusion circuit ran for 60-120 min, after which the perfusate was drained, the skin reopened, and the abdomen inspected and then definitively closed. Resection was graded by the surgeon at the conclusion of the cytoreduction and classified as $\mathrm{R} 0$ for complete macroscopic resection and negative margins on final pathology, R1 for complete macroscopic resection and positive microscopic margins on final pathology, or R2 for incomplete macroscopic resection. R2 was subdivided on the basis of the size of residual disease $(\mathrm{R} 2 \mathrm{a} \leq 5 \mathrm{~mm}, \mathrm{R} 2 \mathrm{~b} \leq 2 \mathrm{~cm}, \mathrm{R} 2 \mathrm{c}>2 \mathrm{~cm}){ }^{24}$

Ascites was considered to have been successfully treated with CRS-HIPEC if all ascites had resolved on routine 3-month postoperative $\mathrm{CT}$. Failures included all patients with reaccumulation of any ascites or recurrence of symptoms attributed specifically to ascites at 3 months.

All data were collected prospectively and analyzed retrospectively. Statistical analyses were performed using SAS 9.3, Cary, NC. Missing data are reported for each variable.

Descriptive statistics are reported for variables using frequencies with percentages or means with ranges as appropriate. In univariate analysis, Fisher's exact test was used to compare categorical values and Wilcoxon rank-sum test to compare continuous variables. Logistic regression was used to calculate odds ratios (OR) for ascites score predicting binary response variables. Survival was estimated using the Kaplan-Meier survival analysis from the date of CRS-HIPEC, and survival curves were compared using the log-rank test. In cases where a patient received more than one CRS-HIPEC, survival was measured from the date of the first procedure. Hazard ratios (HR) were calculated using Cox proportional hazard regression. Confidence intervals $(\mathrm{CI})$ were included where appropriate and $p$ values of 0.05 or less were considered statistically significant.

\section{RESULTS}

Malignant ascites was present in 310 out of 1,000 CRSHIPEC procedures. These procedures were performed in 299 patients. Characteristics of the patients and procedures are listed in Table 1. Minor morbidity (grades I/II) was $36 \%$ (111 of 310). Major morbidity (grades III/IV) was observed in $25 \%$ (79 of 310) of the included patients. ${ }^{25} 30$ and 90-day mortality were 5.8 and $10.6 \%$, respectively.

Ascites scores were able to be calculated in 129 (42\%) of the cases. The remaining cases did not have an accessible preoperative CT scan or a sufficiently detailed operative report. An ascites score of 9 was present in 56 (43\%) of the scored cases. Ascites score, which can be obtained preoperatively, correlated with the degree of resection that would ultimately be achieved. R0/R1 resection was achieved in $15 \%$ of patients with malignant ascites. On the contrary, $59 \%$ (403 of 680) of procedures in patients without malignant ascites had a R0/R1 complete macroscopic cytoreduction $(p<0.001)$. Patients with ascites scores $1-3$ had a 38 $\%$ chance of an R0/R1 resection. This percentage dropped to $10 \%$ in patients with scores 4 6 and to $7 \%$ for scores $7-9(p<0.001)$. Using a logistic regression model, we found that each point increase in ascites score conferred $33 \%$ greater odds of incomplete macroscopic resection (OR 1.33, $95 \%$ CI 1.14-1.55, $p<0.001$ ). In the cohort of scored patients with 
ascites from a low grade appendiceal (LGA) primary tumor $(n=77), \mathrm{R} 0 / \mathrm{R} 1$ resection was achieved in $50 \%$ of cases scored $1-3,9 \%$ scored $4-6$, and $0 \%$ scored $7-9(p=0.001)$. In fact, the odds of incomplete resection doubled for each point increase in ascites score (OR $2.04,95 \%$ CI 1.26-3.30, $p=0.003$ ).

Resolution of malignant ascites occurred in $93 \%$ (288) of the cases. $84 \%$ of successes had a resection with residual macroscopic disease (R2). Ascites failed to resolve in $7 \%$ (22) cases, $86 \%$ of which were $\mathrm{R} 2$ resections. There was no difference in success rate for patients with complete versus incomplete resection $(p=1.00)$. Type of primary tumor $(p=0.19)$, duration ( $p=0.85$ ) or agent $(p=0.34)$ of chemoperfusion, and Eastern Cooperative Oncology Group (ECOG) performance status $(p=0.81)$ were also unable to predict failure (Table 2).

Ascites score could not predict resolution of ascites indicating that resolution of ascites was not dependent on the volume of accumulated fluid $(p=0.35)$. Successful resolution of ascites occurred in $91 \%$ of patients with voluminous ascites (scores of 9) which is not significantly different than the $96 \%$ success rate observed in the remainder of scored patients $(p=0.29)$. In the cohort of patients with voluminous ascites $(n=56)$, success versus failure was not predicted by type of primary tumor $(p=0.54)$, resection status $(p=0.39)$, ECOG performance status ( $p=0.16)$, preoperative chemotherapy $(p=0.33)$, agent ( $p=$ 0.45 ) or duration ( $p=0.57)$ of chemoperfusion, omentectomy ( $p=1.00)$, or number of organs resected $(p=0.32)$.

The median overall survival (OS) of patients with malignant ascites from non-LGA primary disease who had an incomplete cytoreduction ( $\mathrm{R} 2$ resection) was 5.6 months. Complete resection of all macroscopic disease in this cohort conferred a survival benefit (median OS 37 vs. 5.6 months, $p<0.001$ ) (Fig. 2). In patients with LGA primary disease, the resection status was associated with a survival difference that did not reach statistical significance (R0/R1 median OS 85.1 vs. R2 69.3 months, $p=0.33$ ). Higher ascites scores, however, were found to predict worse OS in all scored patients (HR 1.1, $95 \% \mathrm{CI} 1.02-1.21, p=0.02$ ) and in the subset of patients with LGA primary disease (HR 1.3, $95 \%$ CI 1.00-1.74, $p=0.05$ ), but the latter observation was only marginally statistically significant.

\section{DISCUSSION}

The intention of CRS-HIPEC in the presented cohort was to achieve complete cytoreduction, yet the majority of patients with malignant ascites and PSD experienced a secondary benefit of complete resolution of ascites regardless of the completeness of cytoreduction achieved. Although well documented after laparoscopic HIPEC without cytoreduction, data regarding the resolution of ascites after CRS-HIPEC are limited. ${ }^{7,9-21}$ In addition, the presence of ascites obscures tumor deposits on preoperative imaging making it difficult to assess the extent of PSD or calculate an accurate peritoneal carcinomatosis index score before operative exploration. Therefore, the ascites score was created to serve as a tool to predict the likelihood of achieving a complete cytoreduction before attempting CRSHIPEC. 
CRS-HIPEC is $93 \%$ effective in successfully controlling ascites even when a complete cytoreduction is not achieved as a result of the volume or distribution of disease. Malignant ascites successfully resolved in the majority of cases regardless of primary tumor, duration and type of chemoperfusion agent, and ascites score. We observed that resolution of ascites was completely independent of resection status suggesting it is more likely a function of HIPEC than CRS. The published experience with laparoscopic HIPEC for the palliative control of malignant ascites would support this conclusion. The majority of reviews, although small, indicate a high rate of resolution in addition to improvement in quality of life. ${ }^{9-15}$

The presence of malignant ascites significantly decreases the chances of obtaining a complete R0/R1 macroscopic cytoreduction. Calculating the ascites score from a preoperative CT scan, enables the surgeon to predict the odds of a complete cytoreduction and provide the patient with realistic expectations regarding outcomes. Ascites score is a useful tool able to be tabulated quickly and easily without additional cost for the patient because a preoperative $\mathrm{CT}$ is a component of standard preoperative staging. We considered using volumetrics to calculate the volume of ascites in each patient; however, this method would require dedicated software and cannot subtract the volume of solid organs within the ascites. In addition it does not account for the fact that the same volume in a small patient could be associated with significant disease while it might be negligible in a larger patient.

CRS-HIPEC improves survival for patients with malignant ascites only in cases where a complete cytoreduction is achieved. Although higher ascites scores do correlate with worse $\mathrm{OS}$, ascites score is more accurate in predicting which patients will ultimately receive a complete cytoreduction. In patients with LGA primary disease, higher ascites scores exhibited marginally significant worse $\mathrm{OS}(\mathrm{HR}=1.3, p=0.05)$, which is in agreement with current knowledge of survival in patients presenting with high volume disease ${ }^{26}$ However, given the long-term survival experienced by patients with LGA primary disease regardless of resection status achieved, we would argue that operative exploration with attempted CRSHIPEC is merited even in the face of high ascites scores.

Speculation may arise regarding the use of CRS-HIPEC for palliation in patients with malignant ascites from non-LGA primary disease. However, considering the median OS of 5.6 months, most of which will be spent recovering, we would argue against the use of CRSHIPEC in patients with non-LGA primary disease where the goal at the outset is palliation. The high morbidity and less than negligible mortality provide further support for avoiding CRS-HIPEC as a palliative therapy in this cohort. By predicting resection status, ascites score can function as a selection tool for patients presenting as candidates for CRS-HIPEC. For symptomatic non-LGA patients with malignant ascites in which complete cytoreduction is deemed impossible preoperatively, palliative laparoscopic HIPEC without CRS seems to be the better option. Further, should ascites be encountered unexpectedly at the time of laparotomy for a planned CRS-HIPEC, selected patients may benefit from proceeding with the HIPEC portion of the procedure, even if only an R2b or R2c resection can be achieved. 
In conclusion, CRS-HIPEC can control malignant ascites in the majority of patients with incomplete cytoreduction. The presence of malignant ascites is a strong predictor of decreased feasibility achieving a complete macroscopic cytoreduction. Ascites score may be helpful in selecting patients with better chances of complete cytoreduction, thus avoiding CRS-HIPEC in cases where a survival advantage is unlikely to be obtained.

\section{REFERENCES}

1. Chu DZ, Lang NP, Thompson C, Osteen PK, Westbrook KC. Peritoneal carcinomatosis in nongynecologic malignancy. A prospective study of prognostic factors. Cancer. 1989; 63:364-7. [PubMed: 2910444]

2. Garrison RN, Kaelin LD, Galloway RH, Heuser LS. Malignant ascites. Clinical and experimental observations. Ann Surg. 1986; 203:644-51. [PubMed: 3718029]

3. Hind D, Tappenden P, Tumur I, Eggington S, Sutcliffe P, Ryan A. The use of irinotecan, oxaliplatin and raltitrexed for the treatment of advanced colorectal cancer: systematic review and economic evaluation. Health Technol Assess. 2008; 12:iii-ix. xi-162. [PubMed: 18462574]

4. Oh SY, Kwon HC, Lee S, et al. A Phase II study of oxaliplatin with low-dose leucovorin and bolus and continuous infusion 5-fluorouracil (modified FOLFOX-4) for gastric cancer patients with malignant ascites. Jpn J Clin Oncol. 2007; 37:930-5. [PubMed: 18211984]

5. Husain A, Bezjak A, Easson A. Malignant ascites symptom cluster in patients referred for paracentesis. Ann Surg Oncol. 2010; 17:461-9. [PubMed: 19866240]

6. Adam RA, Adam YG. Malignant ascites: past, present, and future. J Am Coll Surg. 2004; 198:9991011. [PubMed: 15194082]

7. Sangisetty SL, Miner TJ. Malignant ascites: a review of prognostic factors, pathophysiology and therapeutic measures. World J Gastrointest Surg. 2012; 4:87-95. [PubMed: 22590662]

8. Kammula, U. Malignant ascites.. In: DeVita, VT.; Hellman, S.; Rosenberg, SA., editors. Cancer: principles and practice of oncology. 9th edition. Lippincott Williams \& Wilkins; Philadelphia: 2011. p. 2214-9.

9. Ba MC, Cui SZ, Lin SQ, et al. Chemotherapy with laparoscope-assisted continuous circulatory hyperthermic intraperitoneal per-fusion for malignant ascites. World J Gastroenterol. 2010; 16:1901-7. [PubMed: 20397270]

10. Chang E, Alexander HR, Libutti SK, et al. Laparoscopic continuous hyperthermic peritoneal perfusion. J Am Coll Surg. 2001; 193:225-9. [PubMed: 11491455]

11. de Mestier L, Volet J, Scaglia E, Msika S, Kianmanesh R, Bouche O. Is palliative laparoscopic hyperthermic intraperitoneal chemotherapy effective in patients with malignant hemorrhagic ascites? Case Rep Gastroenterol. 2012; 6:166-70. [PubMed: 22679405]

12. Facchiano E, Scaringi S, Kianmanesh R, et al. Laparoscopic hyperthermic intraperitoneal chemotherapy (HIPEC) for the treatment of malignant ascites secondary to unresectable peritoneal carcinomatosis from advanced gastric cancer. Eur J Surg Oncol. 2008; 34:154-8. [PubMed: 17640844]

13. Garofalo A, Valle M, Garcia J, Sugarbaker PH. Laparoscopic intraperitoneal hyperthermic chemotherapy for palliation of debilitating malignant ascites. Eur J Surg Oncol. 2006; 32:682-5. [PubMed: 16631341]

14. Graziosi L, Bugiantella W, Cavazzoni E, Donini A. Laparoscopic intraperitoneal hyperthermic perfusion in palliation of malignant ascites. Case report. G Chir. 2009; 30:237-9.

15. Valle M, Van der Speeten K, Garofalo A. Laparoscopic hyper-thermic intraperitoneal peroperative chemotherapy (HIPEC) in the management of refractory malignant ascites: a multi-institutional retrospective analysis in 52 patients. J Surg Oncol. 2009; 100:331-4. [PubMed: 19697441]

16. Hill AR, McQuellon RP, Russell GB, Shen P, Stewart JH, Levine EA. Survival and quality of life following cytoreductive surgery plus hyperthermic intraperitoneal chemotherapy for peritoneal carcinomatosis of colonic origin. Ann Surg Oncol. 2011; 18:3673-9. [PubMed: 21674272] 
17. McQuellon RP, Danhauer SC, Russell GB, et al. Monitoring health outcomes following cytoreductive surgery plus intraperitoneal hyperthermic chemotherapy for peritoneal carcinomatosis. Ann Surg Oncol. 2007; 14:1105-13. [PubMed: 17206478]

18. Tsilimparis N, Bockelmann C, Raue W, et al. Quality of life in patients after cytoreductive surgery and hyperthermic intraperitoneal chemotherapy: is it worth the risk? Ann Surg Oncol. 2013; 20:226-32. [PubMed: 22868919]

19. Gilly FN, Carry PY, Brachet A, et al. Treatment of malignant peritoneal effusion in digestive and ovarian cancer. Med Oncol Tumor Pharmacother. 1992; 9:177-81. [PubMed: 1342062]

20. Loggie BW, Perini M, Fleming RA, Russell GB, Geisinger K. Treatment and prevention of malignant ascites associated with disseminated intraperitoneal malignancies by aggressive combined-modality therapy. Am Surg. 1997; 63:137-43. [PubMed: 9012427]

21. Yonemura Y, Fujimura T, Fushida S, et al. Hyperthermo-chemotherapy combined with cytoreductive surgery for the treatment of gastric cancer with peritoneal dissemination. World $\mathrm{J}$ Surg. 1991; 15:530-5. [PubMed: 1891941]

22. Jacquet $P$, Sugarbaker $P H$. Clinical research methodologies in diagnosis and staging of patients with peritoneal carcinomatosis. Cancer Treat Res. 1996; 82:359-74. [PubMed: 8849962]

23. Levine EA, Stewart JH, Russell GB, Geisinger KR, Loggie BL, Shen P. Cytoreductive surgery and intraperitoneal hyperthermic chemotherapy for peritoneal surface malignancy: experience with 501 procedures. J Am Coll Surg. 2007; 204:943-53. [PubMed: 17481516]

24. Edge, SB.; Fritz, AG.; Byrd, DR., et al. AJCC cancer staging manual. 7th edition. Springer; New York: 2010.

25. Dindo D, Demartines N, Clavien PA. Classification of surgical complications: a new proposal with evaluation in a cohort of 6,336 patients and results of a survey. Ann Surg. 2004; 240:205-13. [PubMed: 15273542]

26. Chua TC, Moran BJ, Sugarbaker PH, et al. Early- and long-term outcome data of patients with pseudomyxoma peritonei from appendiceal origin treated by a strategy of cytoreductive surgery and hyperthermic intraperitoneal chemotherapy. J Clin Oncol. 2012; 30:2449-56. [PubMed: 22614976] 


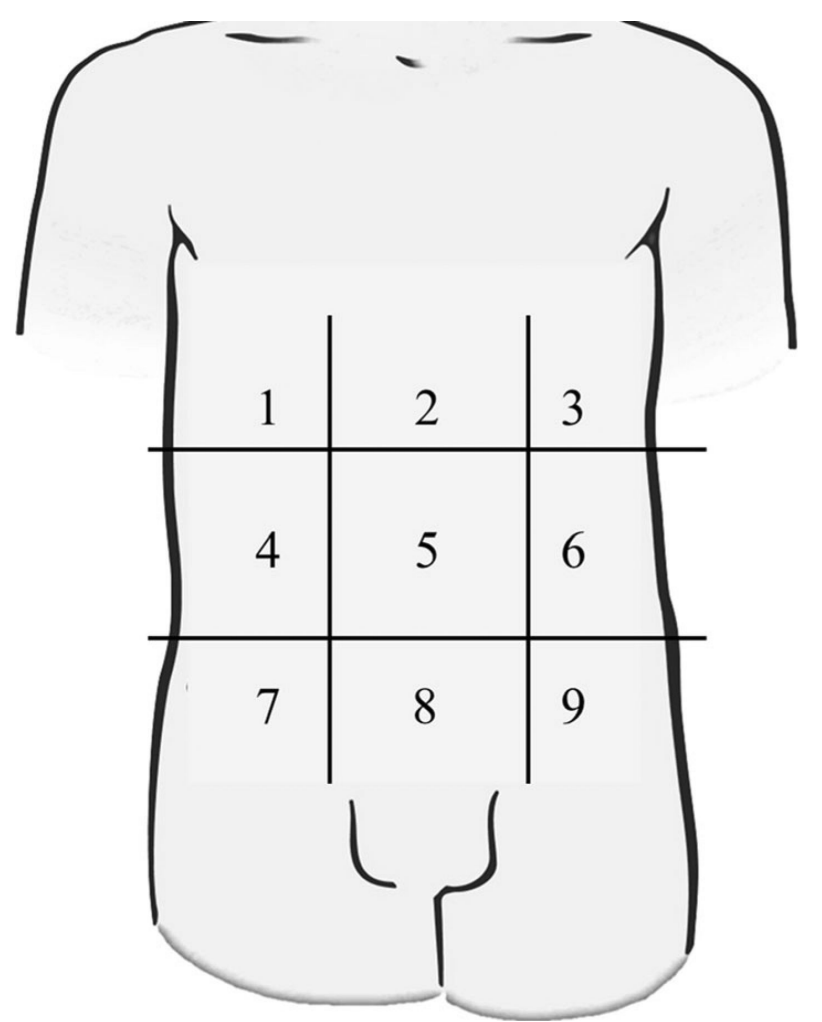

FIG. 1.

Peritoneal cavity regions for calculating ascites score. One point is given for the presence of ascites in each of nine regions on supine computed tomography 

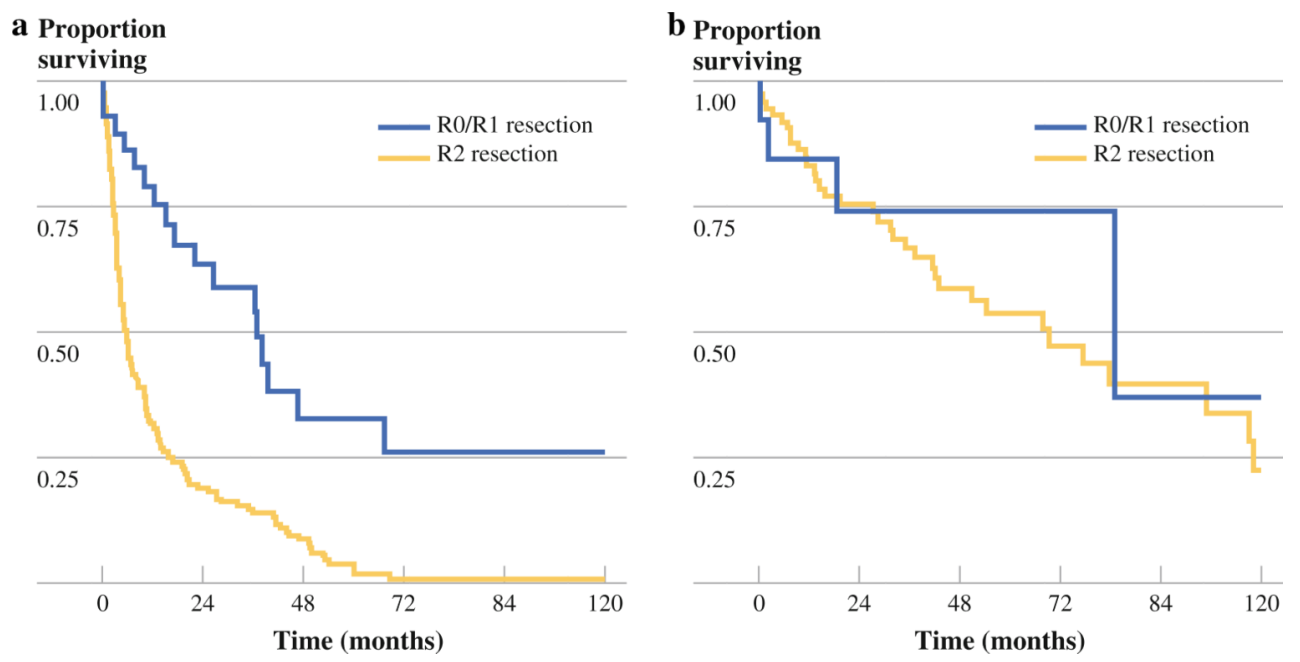

FIG. 2.

Survival based on resection status in patients with malignant ascites and a non-LGA primary and $\mathrm{b}$ LGA primary 


\section{TABLE 1}

Patient and procedure characteristics ( $n=310$ procedures)

\begin{tabular}{|c|c|}
\hline Characteristic & Value \\
\hline Female sex, $n(\%)$ & $158(51)$ \\
\hline Age (years), mean (range) & $53.2(11-87)$ \\
\hline Diabetes, $n(\%)^{a}$ & $31(11)$ \\
\hline Heart disease, $n(\%)^{a}$ & $29(10)$ \\
\hline Lung disease, $n(\%)^{a}$ & $18(6)$ \\
\hline \multicolumn{2}{|l|}{ ECOG, $n(\%)^{b}$} \\
\hline 0 & $86(28)$ \\
\hline 1 & $134(43)$ \\
\hline 2 & $65(21)$ \\
\hline 3 & $22(7)$ \\
\hline \multicolumn{2}{|l|}{ Type of primary disease, $n(\%)$} \\
\hline Appendiceal & $142(46)$ \\
\hline Colorectal & $53(17)$ \\
\hline Gastric & $20(6)$ \\
\hline Mesothelioma & $45(15)$ \\
\hline Ovarian & $26(8)$ \\
\hline Other & $34(11)$ \\
\hline Organs resected, mean (range) & $3.2(0-8)$ \\
\hline Omentectomy, $n(\%)$ & $196(63)$ \\
\hline \multicolumn{2}{|l|}{ Resection type, $n(\%)^{b}$} \\
\hline $\mathrm{R} 0 / 1$ & $47(15)$ \\
\hline $\mathrm{R} 2 \mathrm{a}$ & $105(34)$ \\
\hline $\mathrm{R} 2 \mathrm{~b}$ & $73(24)$ \\
\hline $\mathrm{R} 2 \mathrm{c}$ & $82(27)$ \\
\hline \multicolumn{2}{|l|}{ Chemotherapeutic agent } \\
\hline Mitomycin C & $258(83)$ \\
\hline Carboplatin & $10(3)$ \\
\hline Cisplatin & $26(8)$ \\
\hline Oxaliplatin & $19(6)$ \\
\hline \multicolumn{2}{|l|}{ Duration of perfusion $(\min )^{b}$} \\
\hline $60-89$ & $23(7)$ \\
\hline $90-119$ & $46(15)$ \\
\hline $120+$ & $239(78)$ \\
\hline \multicolumn{2}{|c|}{ ECOG Eastern Cooperative Oncology Group } \\
\hline $6 \%$ missing & \\
\hline
\end{tabular}


TABLE 2

Univariate analysis of predictors of recurrent ascites after CRS-HIPEC

\begin{tabular}{|c|c|c|c|}
\hline Characteristic & Success $(n=288)$ & Failure $(n=22)$ & $p$ value \\
\hline Female sex, $n(\%)$ & $146(51)$ & $12(55)$ & 0.83 \\
\hline Age (years), mean (range) & $53.5(11-87)$ & $50.0(24-78)$ & 0.17 \\
\hline ECOG, $n(\%)$ & & & 0.81 \\
\hline $0 / 1$ & $205(71)$ & $15(68)$ & \\
\hline$\geq 2$ & $80(28)$ & $7(32)$ & \\
\hline Preoperative chemotherapy, $n(\%)$ & $120(42)$ & $8(40)$ & 0.65 \\
\hline Type of primary disease, $n(\%)$ & & & 0.19 \\
\hline Appendiceal & $135(47)$ & $7(32)$ & \\
\hline Colorectal & $49(17)$ & $4(18)$ & \\
\hline Gastric & $18(6)$ & $2(9)$ & \\
\hline Mesothelioma & $39(14)$ & $6(27)$ & \\
\hline Ovarian & $26(9)$ & 0 & \\
\hline Unknown & $10(3)$ & $1(5)$ & \\
\hline Other & $11(4)$ & $2(9)$ & \\
\hline Ascites score, $n(\%)$ & & & 0.35 \\
\hline $1-3$ & $33(29)$ & $1(14)$ & \\
\hline $4-6$ & $20(17)$ & 0 & \\
\hline $7-9$ & $62(54)$ & $6(86)$ & \\
\hline No. of organs resected, mean (range) & $3.2(0 \mathrm{v} 8)$ & $2.8(0 \mathrm{v} 7)$ & 0.17 \\
\hline Omentectomy, $n(\%)$ & $182(63)$ & $14(64)$ & 1.00 \\
\hline Resection type, $n(\%)$ & & & 1.00 \\
\hline $\mathrm{R} 0 / 1$ & $44(15)$ & $3(14)$ & \\
\hline $\mathrm{R} 2$ & $243(84)$ & $19(86)$ & \\
\hline Positive nodes, $\mathbf{n}(\%)$ & $63(22)$ & $6(27)$ & 0.33 \\
\hline Chemotherapeutic agent & & & 0.34 \\
\hline Mitomycin C & $241(84)$ & $17(77)$ & \\
\hline Carboplatin & $10(3)$ & 0 & \\
\hline Cisplatin & $22(8)$ & $4(18)$ & \\
\hline Oxaliplatin & $18(6)$ & $1(5)$ & \\
\hline \multicolumn{4}{|l|}{ Duration of perfusion, $\mathbf{n}(\%)$} \\
\hline $60-89 \min$ & $22(8)$ & $1(5)$ & \\
\hline $90-119 \min$ & $42(15)$ & $4(18)$ & \\
\hline $120+\min$ & $222(77)$ & $17(77)$ & \\
\hline Hospital length of stay (days), mean (range) & $17.9(1-157)$ & $13.5(5-37)$ & 0.55 \\
\hline
\end{tabular}

CRS cytoreductive surgery, HIPEC hyperthermic intraperitoneal chemotherapy, ECOG Eastern Cooperative Oncology Group 